\title{
Missing the target — infant mortality in India
}

I ndia needs to focus more attention on the social determinants of health, the empowerment of women and preventive health, as well as reduce births among adolescent girls, if it is to possibly achieve the Millennium Development Goal (MDG) of reducing under-five infant mortality rates by two-thirds between 1990 and 2015.

But it is unlikely to do so, according a report, Infant and Child Mortality in India Levels, Trends and Determinants, symbolically released on Children's Day in India (Nov. 14) by UNICEF, the National Institute of Medical Statistics and the Indian Council of Medical Research (www.unicef.org/india/Report .pdf). The report projects that India will only lower its under-five mortality rate to 52 deaths per 1000 live births by 2015 , rather than the MDG target of 39.

The government, however, contends that the rate will drop to 34 deaths per 1000 live births. "Between 2008 and 2010, Under Five Mortality Rate has declined by 5 points each year. At this pace of decline, the Under Five Mortality in 2015 is expected to be 34 , which is lower than [the] goal under MDG," it stated in a press release (available at: http://pib.nic.in/newsite/erelease.aspx ?relid=8252).

Several Indian experts appeared unconvinced by the extrapolation and urged more aggressive measures to reduce deficiencies identified in the report, including the lack of maternal education for women with little schooling, and the higher infant mortality rates among children born to adolescent mothers, or born within two years of a previous pregnancy.

"We need to collectively have increased focus on women empowerment — girls' education, reduce gender disparities among boys and girls and improve adolescent health including delaying pregnancies," says Dr. Pavitra Mohan, health specialist in UNICEF's India Country Office.

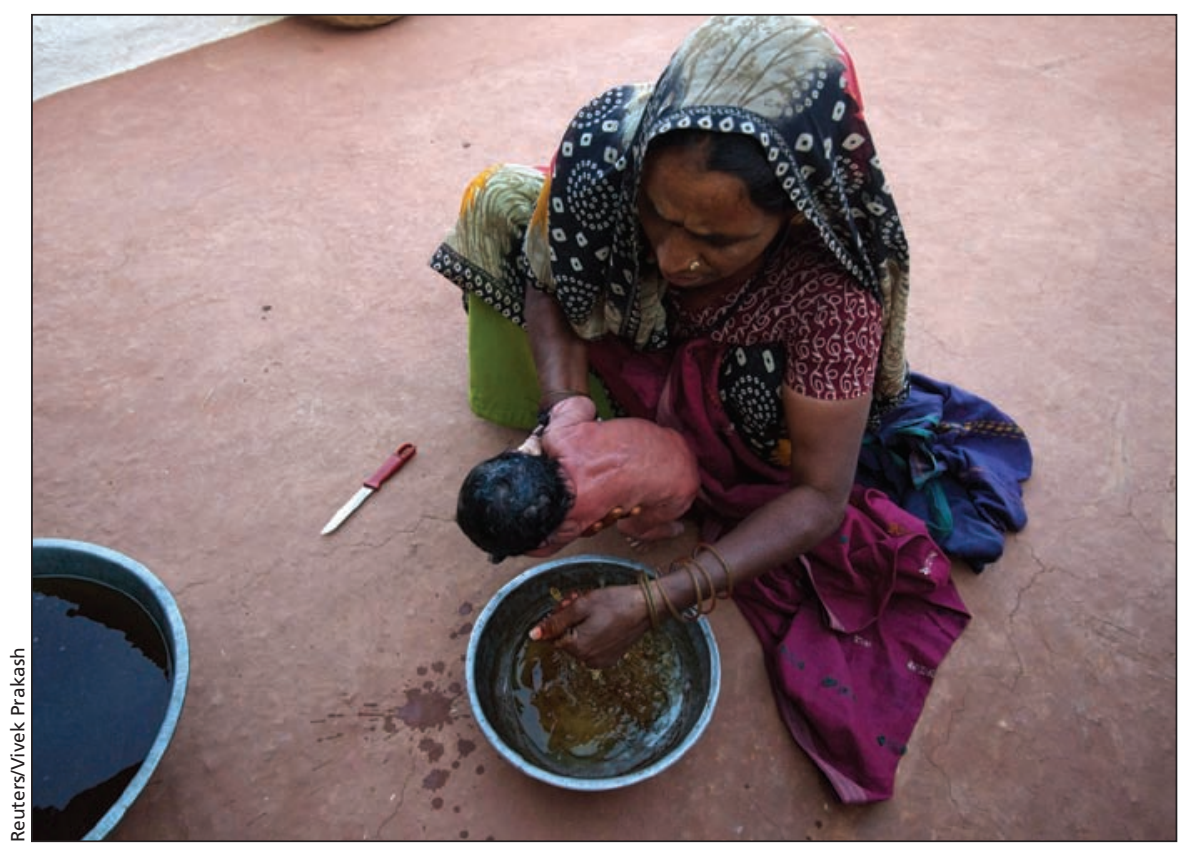

A woman bathes the newborn baby of a relative in a rural area of India near the remote village of Chharchh, in the central state of Madhya Pradesh.

"Women empowerment" must also be addressed, says Dr. Rohit Agrawal, president of the Indian Academy of Pediatrics. "The child and the mother are one unit."

Others argued that India's response must include efforts to redress social inequities. The "focus of [the] health system in India is largely on medicine and not on health," says Dr. Chandrakant Pandav, head of the Centre for Community Medicine at the All India Institute of Medical Sciences in New Delhi. "Health care in India does not address other factors like education, sanitation, standard of living and income generation. The need of the hour is to have better coordination between various agencies implementing health and health-related programmes in order to have desired outcomes."

Mohan concurs, arguing that the inability to reach the MDG goal is a function of excessive pressures on the health system and inadequate use of successful interventions such as contraceptives.
For its part, the Indian Academy of Pediatrics says it will launch an "Anemia Free Pink India" program to reduce iron deficiency among pregnant women, as well as train 273000 health workers in neonatal resuscitation by 2015 .

Significantly, the report also indicates that some Indian states are more advanced in reducing infant mortality rates than others. That's a function of a "combination of higher status of women and maternal education and improved health system (Kerala and Himachal Pradesh); in some, improved health systems (Maharashtra); in some, only maternal education (Himachal Pradesh); and in some, prosperity (Punjab)," Pandav says.

Meanwhile, Mohan says that the Indian Council of Medical Research will conduct "public policy debates ... to further cull out implications [of the report] and inputs for policy and planning." - Soumyadeep Bhaumik MBBS, Kolkata, India

CMAJ 2013. DOI:10.1503/cmaj.109-4366 